\title{
Hemispheric differences in stimulus identification
}

\author{
JOHN M. POLICH \\ University of Wisconsin-Parkside, Kenosha, Wisconsin 53141
}

\begin{abstract}
Subjects were presented with either verbal (letters) or nonverbal (outline forms) stimuli to their left or right cerebral hemispheres. Verbal items presented with a lateral masking stimulus were identified more quickly and accurately when presented to the right hemisphere rather than to the left. When the letters were presented without a masking stimulus, weak hemispheric effects were obtained. Nonverbal forms demonstrated faster reaction time and fewer errors for right-hemisphere presentations under both masked and unmasked conditions. Retinal locus of the display item was also varied and produced faster responding with fewer errors when the stimulus was presented foveally rather than peripherally under all display conditions. These effects were attributed to the use of a manual response procedure that effectively reduced the ability of subjects to employ names for the stimulus objects.
\end{abstract}

The usual paradigm for measuring hemispheric processing effects on the accuracy of stimulus identification consists of tachistoscopically presenting items in either the right or left visual field. If the subject is fixating on a central point and the stimulus is presented at an exposure duration of less than $250 \mathrm{msec}$, the item is projected to the hemisphere contralateral to the visual field in which it appears. The subject is then required to indicate, either verbally or by pointing to the test item from an array of possible items, what he saw. Considering identification studies that presented stimulus items to only one visual field on any given trial, verbal items are correctly identified more often when they are projected to the left than when they are projected to the right hemisphere. These verbal stimulus materials have included single letters (Bryden, 1965, 1966; Bryden \& Rainey, 1963; Hines, Satz, \& Clementino, 1973; Kimura, 1966; McKeever \& Gill, 1972b; Worral \& Coles, 1976), letter strings (Cohen, 1976; Fontenot, 1973; Fontenot \& Benton, 1972; Hannay \& Malone, 1976; Hilliard, 1973; Neil, Sampson, \& Gribben, 1971; White, 1969, 1971), and words (Forgays, 1953; Mishkin \& Forgays, 1952; McKeever \& Huling, 1970; Orbach, 1953).

Similar findings have been obtained when reaction time (RT) is used to measure hemispheric differences for speed of stimulus identification. When vocal RT

\footnotetext{
This paper is based on research conducted for a Phd Dissertation at Dartmouth College. I thank George Wolford, Fred Morrison, and Carol Fowler for serving on the committee. Requests for reprints should be addressed to the author, who is now at the Cognitive Psychophysiological Laboratory, Department of Psychology, University of Illinois, Champaign, Illinois 61820 .
}

is measured, the subject is required to name the stimulus. Faster responding has been observed for left hemisphere presentations of verbal items than for right hemisphere presentations (Carmon, Nachshon, Isseroff, \& Kleiner, 1972; Cohen, 1975; Isseroff, Carmon, \& Nachshon, 1974; McKeever \& Gill, 1972a; McKeever, Gill, \& VenDeventer, 1975; Moscovitch \& Catlin, 1970; White, 1973). If manual RT is the dependent variable, the subject's task is to press a button whenever a specific item from a set of possible items is presented. For verbal stimulus items, manual $\mathrm{RT}$ is also shorter for left hemisphere than for right hemisphere projections (Isseroff et al., 1974; Rizzolatti, Umilta, \& Berlucchi, 1971; Umilta, Frost, \& Hyman, 1972; White, 1973a).

Because of the nature of the stimuli, identification accuracy for nonverbal stimulus items is usually measured by initially presenting the subject with a target stimulus or group of stimuli for memorization and then projecting a test stimulus to the left or right hemisphere. The subject's task is to indicate whether or not the test stimulus was the same as the target stimulus or a member of a positive subset of the group of items. When faces have been used as nonverbal stimulus materials, this procedure has demonstrated superior accuracy for right hemisphere presentations (Hilliard, 1973; Young \& Ellis, 1976). Similar results have been obtained with solid random shapes (Dee \& Fontenot, 1973; Fontenot, 1973). In addition, manual RT for faces as nonverbal stimuli is shorter when the test stimulus items are presented to the right hemisphere for identification rather than the left (Geffen, Bradshaw, \& Wallace, 1971; Moscovitch, Scullion, \& Christie, 1976; Rizzolatti, Umilta, \& Berlucchi, 1971). 
A second class of nonverbal stimulus materials, however, has not demonstrated consistent hemispheric differences for accuracy in identification. When geometric forms (e.g., squares, circles, etc.) or outlines of common objects (e.g., tree, house, etc.) are used as nonverbal stimuli and the subject is to identify the object by name or by pointing, generally no hemispheric differences have been observed for identification accuracy (Bryden, 1960, 1973; Bryden \& Rainey, 1963; Kimura, 1966; Kimura \& Dunford, 1974; Wyke \& Ettlinger, 1961). Occasionally, lefthemisphere presentations have yielded superior performance (Paivio \& Ernest, 1971). Inconsistent results have also been obtained for these nonverbal stimuli when manual RT is employed as the dependent measure (Juola, 1973; Klatzky \& Atkinson, 1971; Umilta, Rizzolatti, Marzi, Zamboni, Franzini, Camarda, \& Berlucchi, 1974).

Thus, identification performance for verbal stimulus materials has demonstrated consistent lefthemisphere effects, but the identification performance for nonverbal stimulus materials has demonstrated inconsistent hemispheric effects. An important consideration in cvaluating these results is the effect of the identification task itself. For studies employing accuracy or vocal RT as the dependent variable, the subject literally names the item to identify it. When manual RT is employed, the subject usually identifies the test stimulus by matching it to a target item or to a positive subset taken from a larger pool of items. Naming the item would necessarily involve a verbal code for the stimulus (Posner \& Mitchell, 1967; Posner, 1969) and therefore the language capabilities of the left hemisphere (Cohen, 1972; Gazzaniga \& Sperry, 1967; Geffen, Bradshaw, \& Nettleton, 1972; Geschwind, 1970; Levy \& Trevarthen, 1976; Milner, 1971). When the stimulus matching paradigm is used, however, the subject is responding manually and the opportunity for using explicit stimulus labels is greatly reduced, thereby encouraging some form of visual coding (Bartram, 1974; Klatzky, 1972). Thus, mentally matching a target item to previously memorized items could require a holistic or visuospatial process, a primary attribute of the right hemisphere (Bogen, 1969; Levy, 1974; Levy, Trevarthen, \& Sperry, 1972; Paterson \& Zangwill, 1944; Sperry, 1974). These two Types of responses, then, stimulus naming and stimulus matching, each generate task demands that could affect hemispheric differences for stimulus identification.

Accuracy studies have generally employed stimulus naming to identify both verbal and "nonverbal" items (e.g., common objects and geometric forms). Since the naming procedure itself would employ lefthemisphere processing, it could greatly reduce or even reverse any potential right-hemisphere effects (e.g., Bryden, 1960; Kimura, 1966; Paivio \& Ernest,
1971). Thus, the influence of the type of stimulus on identification performance for this task is difficult to determine. A matching-to-memory procedure, by eliminating any overt stimulus labeling, could provide a means to evaluate just the effects of the type of stimulus, but very few studies have employed such a task for both types of stimulus materials. When this has been done with outlines of common objects as the nonverbal stimuli and letters or words as the verbal stimuli, inconsistent hemispheric effects have been obtained (Juola, 1973; Klatzky \& Atkinson, 1971), possibly because the outline forms have readily available labels (e.g., "tree," "house," etc.) which could affect hemispheric differences for stimulus identification. However, when faces have been used as nonverbal stimuli and letters as verbal stimuli in a matching task, RT was shorter for righthemisphere presentations of the faces and lefthemisphere presentations of the letters (Rizzolatti et al., 1971)-the classic specialization for types of stimulus finding.

Given these few studies and their various findings, one cannot determine whether hemispheric differences for stimulus identification, within a nonnaming response paradigm, are due to the specific type of stimulus (i.e., faces/solid objects) or to the task demands of memory matching. The present study was designed to help clarify this situation by employing a well-practiced manual identification task for both verbal stimuli (letters) and nonverbal outline stimuli (label resistant forms). If the primary determinant of hemispheric differences in stimulus identification is the availability of a label for a stimulus item, then verbal stimuli should demonstrate shorter RT for left-hemisphere presentations, while the nonverbal stimuli should demonstrate shorter RT for the right-hemisphere presentations, despite the type of response situation. However, if the memory matching response task controls the outcome of hemispheric differences, then both verbal and nonverbal stimulus items should demonstrate short RT for righthemisphere presentations, since the subject must employ a nonnaming strategy for both types of stimuli.

In addition to the type of stimulus and type of response task, two other variables relevant to stimulus identification were investigated. The presence of a stimulus item with similar features to the target item on either side of the target item can act as a lateral mask to affect stimulus identification (Hollingsworth \& Wolford, cited in Wolford, 1975; Wolford, 1975) and has demonstrated some hemispheric effects (Bouma, 1974; Bradshaw, Bradley, Gates, \& Patterson, 1977). The retinal locus of the stimulus image has also been shown to affect identification of verbal stimuli (Estes \& Wolford, 1971; Hershenson, 1969; White, 1970; Wolford \& 
Hollingsworth, 1974) and has demonstrated some hemispheric differences (Hirata \& Bryden, 1976; Lefton \& Haber, 1974; McKeever \& Gill, 1972a; Scheerer, 1974; White, 1973b; Wolford \& Hollingsworth, 1974). Therefore, to help clarify the influence of lateral masking and retinal locus effects on hemispheric differences and to extend these findings to nonverbal stimulus items, these variables were included in the present study.

\section{METHOD}

\begin{abstract}
Subjects
A total of 16 subjects were employed. Eight of these responded to verbal stimuli and eight responded to nonverbal stimuli, with an equal number of males and females within each stimulus condition. All subjects were dextrals without any sinistrality in their immediate families. All subjects had normal or corrected-to-normal vision and received course credit for their participation.
\end{abstract}

\section{Materials}

Stimuli for the verbal condition consisted of the capital letters $\mathrm{K}, \mathrm{T}, \mathrm{Y}$, and $\mathrm{Z}$. Stimuli for the nonverbal condition consisted of the forms $\mathrm{G}, \mathrm{Z}, \mathrm{Q}$, and $\mathrm{H}$. The latter took significantly longer to label and were judged significantly more nonverbal, unfamiliar, and meaningless than the letters of the alphabet, common typographical symbols, and various other shapes and line figures in a pretest. ${ }^{1}$ All stimulus items were $.4^{\circ}$ wide and $.6^{\circ}$ high.

The stimuli were presented on a Data Media Elite 1520A cathode ray tube (CRT) computer terminal. The terminal had been modified to allow presentation of the nonverbàl items via software control. The screen of the CRT was covered with a black paper mask such that only a display area of the screen measuring $18^{\circ} \times .8^{\circ}$ was visible to the subject. Attached to the CRT console was a viewport tube measuring $15 \times 15 \mathrm{~cm}$ square and $35 \mathrm{~cm}$ long. The viewport kept the subject's head orientation and viewing distance constant and provided a means of focusing the subject's gaze on the stimulus presentation area. The keyboard of the terminal was covered with a black Plexiglas cover such that only the external buttons controlling the keyboard characters Q, D, J, and @ were operational. These characters were chosen as the response keys because their locations on the keyboard produced approximately equal spacing for the first two fingers of the subject's left and right hands.

A Polytronic Universal Response Timer (Model 401 A) was used to record the subject's response and reaction time to an accuracy of $\pm .01 \mathrm{msec}$. The timer was interfaced between the CRT and a time-sharing computer and measured the time from the onset of the stimulus display to the subject's buttonpress response (see Potts, 1976). The responses and reaction times for each trial were transmitted and stored automatically in the computer. All stimulus presentations and data collection were under software control. The apparatus was located in a small laboratory room with only the signal from the terminal telephone coupler providing minimal illumination during the experimental trials. The height of the viewport and chair were adjusted for each subject.

\section{Design}

Each subject within a stimulus set condition received all experimental treatments. The independent variables were visual field (left vs. right), presence of lateral mask (masked vs. unmasked), and retinal locus $\left(1.9^{\circ}\right.$ vs. $\left.3.8^{\circ}\right)$. When factorially combined with each of the four stimulus items of either the verbal or nonverbal set, a total of 32 different combinations of stimulus presentation conditions produced one block of trials. Each subject was run for five blocks in a session, for a total of six sessions, distributed over 3 days.
Each stimulus item was displayed for $153 \mathrm{msec}$ (the display and stimulus control times resulted from the hardware constraints of the system). The retinal locus of the display was varied by manipulating the distance from the subject's center of fixation to the location of the stimulus item. When the stimulus display was masked, the target item was presented with a rectangle of the same size as the letters and nonverbal items on either side of the stimulus (e.g., $\square \mathrm{K} \square$ or $\square \square \square$ ). When the stimulus was presented in the unmasked condition, just the target item was presented in one of the four possible locations.

Each of the four available response keys represented one of the four possible stimulus items. The subject rested the index and second fingers of his left hand on the buttons corresponding to the $Q$ and $D$ keys and the same two fingers of his right hand on the buttons corresponding to the $\mathrm{J}$ and $@$ keys. The assignment of specific key to stimulus character was random for each subject, although no two subjects had the same order. In addition, the stimulus presentation sequence for each block of 32 trials was randomized for each subject.

\section{Procedure}

Subjects were run individually. They were shown a card that illustrated the four stimulus items in the same order as their button response sequence (e.g., if the response button sequence was from left to right-K, T, Y, Z-the card illustrated the same order). They were told to remember the particular stimulus items and to note the assignment of each item to its response button. They were then shown examples of the left and right visual field presentations, the different possible retinal locations; and the masked and unmasked stimulus items. The subjects were instructed to maintain central fixation. They were informed that the stimulus items for each trial would be "flashed" to any one of the four possible presentation positions. They were told that their task was to press the button that corresponded to the item they perceived. The experimenter emphasized that speed was a primary requirement for the task, but that they were not to sacrifice accuracy.

The sequence of events for each trial was as follows: When the subject was ready to begin a block of trials, he pressed one of the response buttons designated previously as the control button. A few seconds later, a fixation cross appeared in the middle of the presentation field and an electronic tone sounded. This was the subject's signal to fixate on the cross and to prepare for the stimulus item. Approximately $1 / 2 \mathrm{sec}$ later $(493 \mathrm{msec})$, the fixation cross disappeared and the stimulus display occurred in one of the target areas. The subject then responded by depressing the response button which had been assigned to the stimulus item he saw. If the subject was correct, he heard one tone; if he had made an error, he heard two tones. The next trial occurred automatically 5 to $7 \mathrm{sec}$ after the feedback had been given. This same sequence continued for the 32 trials of a given block. A series of four tones alerted the subject to the end of a block and to the beginning of a $45-\mathrm{sec}$ rest period. At this time, the subject was shown his mean correct reaction time and his percentage of correct responses for the block of trials. A single tone signaled the end of the rest period (although subjects were permitted to rest longer if they wished). The next block was initiated by depressing a control button. After five such blocks, the subject was required to rest for a minimum of $5 \mathrm{~min}$ before continuing. The subject performed another five blocks to complete a single day's trials. The two sessions and rest period lasted a total of $1 \mathrm{~h}$ and $15 \mathrm{~min}$. The subject repeated this sequence for 3 days. At the end of the 3rd day, the subject was debriefed about the nature of the experiment.

\section{RESULTS}

Both RT and accuracy data were recorded. The data obtained from the first two sessions were considered as practice and excluded from all statistical 
Table 1

Mean Reaction Time (RT) in Milliseconds and Percentage of Incorrect Responses (IR) for All Stimulus Conditions

\begin{tabular}{|c|c|c|c|c|c|c|c|c|c|c|c|c|c|c|c|c|}
\hline \multirow[b]{4}{*}{ Hemisphere } & \multicolumn{8}{|c|}{ Verbal } & \multicolumn{8}{|c|}{ Nonverbal } \\
\hline & \multicolumn{4}{|c|}{ Unmasked } & \multicolumn{4}{|c|}{ Masked } & \multicolumn{4}{|c|}{ Unmasked } & \multicolumn{4}{|c|}{ Masked } \\
\hline & \multicolumn{2}{|c|}{$1.9^{\circ}$} & \multicolumn{2}{|c|}{$3.8^{\circ}$} & \multicolumn{2}{|c|}{$1.9^{\circ}$} & \multicolumn{2}{|c|}{$3.8^{\circ}$} & \multicolumn{2}{|c|}{$1.9^{\circ}$} & \multicolumn{2}{|c|}{$3.8^{\circ}$} & \multicolumn{2}{|c|}{$1.9^{\circ}$} & \multicolumn{2}{|c|}{$3.8^{\circ}$} \\
\hline & RT & IR & RT & IR & RT & IR & RT & IR & RT & IR & RT & IR & $\mathrm{RT}$ & IR & RT & IR \\
\hline Left & 453 & 4.5 & 469 & 4.9 & 538 & 6.8 & 607 & 16.4 & 570 & 2.7 & 694 & 23.8 & 685 & 14.6 & 856 & 41.4 \\
\hline Right & 453 & 4.3 & 462 & 4.7 & 516 & 8.6 & 579 & 10.4 & 533 & 2.2 & 624 & 11.7 & 633 & 10.2 & 779 & 27.9 \\
\hline
\end{tabular}

analyses. The data obtained from the first block of 32 trials for each of the four remaining experimental sessions were considered as warm-up and excluded from all statistical analyses. All RTs greater than $2 \mathrm{sec}$ were considered as errors (these were mainly equipment failures and accounted for less than $.5 \%$ of all responses). All trials on which response errors occurred were dropped from the RT analysis. Reaction times within a trial block were averaged over the four different stimuli within each stimulus condition. If a subject made an error on one of these four trials, it was not included in the averaging process. However, the proportion of errors was computed using the total number of experimental trials.

\section{Reaction Time Data}

The RTs averaged over the eight subjects for each stimulus condition are presented in Table 1. Each mean represents 512 presentations for a particular stimulus viewing condition. A four-factor (Hemisphere by Stimulus Type by Masking Condition by Visual Angle) analysis of variance was performed on the mean RT of each subject's experimental trials for each stimulus viewing condition. An overall significant main effect for the hemisphere of projection was obtained, $F(1,14)=13.8, p<.01$, with the right hemisphere demonstrating shorter identification RT than the left ( 572 vs. $609 \mathrm{msec}$ ). The verbal stimulus items produced significantly shorter response times than the nonverbal stimulus items $(510$ vs. $672 \mathrm{msec})$, with $F(1,14)=12.0$, $p<.01$. These two factors, hemisphere of projection and type of stimulus interacted significantly, $F(1,14)$ $=5.2, \mathrm{p}<.05$, and reflect the larger difference in RTs between the left- and right-hemisphere presentations for nonverbal stimuli $(59 \mathrm{msec})$ as compared to the hemispheric differences for verbal stimuli $(14 \mathrm{msec})$. This interaction is important, as it implies that the two types of stimuli were treated differently by the left and right hemispheres.

RT for both sets of stimulus items was significantly longer in the masked condition than in the unmasked condition ( 649 vs. $532 \mathrm{msec}$ ), with $F(1,14)=100.2, p<.001$. In addition, retinal locus of the stimulus item also significantly affected identification speed, $\mathrm{F}(1,14)=44.6, \mathrm{p}<.001$, with the $1.9^{\circ}$ presentations producing faster responding than the $3.8^{\circ}$ presentations (548 vs. $634 \mathrm{msec}$ ). Retinal locus interacted significantly with the presence of a lateral mask, $F(1,14)=18.8, p<.001$, indicating a smaller difference between masked and unmasked items when they were presented nearer the fovea than when they were presented away from the fovea ( $91 \mathrm{vs.} 143 \mathrm{msec}$ ). The retinal locus of the stimulus display also interacted significantly with stimulus type, $\mathrm{F}(1,14)=12.9, \mathrm{p}<.01$, reflecting a shorter response time difference between verbal and nonverbal stimuli for displays presented near the fovea (115) than for displays presented away from the fovea ( $209 \mathrm{msec}$ ).

Because stimulus type interacted significantly with the hemisphere of projection, the RT data from the verbal and nonverbal stimulus conditions were analyzed separately with a three-factor analysis of variance (Hemisphere by Masking Condition by Visual Angle). For the verbal stimuli, hemisphere of projection demonstrated only a marginally significant main effect, $F(1,7)=4.8, p=.06$, with the right hemisphere producing shorter identification RT than the left $(503$ vs. $517 \mathrm{msec})$. This effect appears to have resulted from the significant interaction between the masking condition and hemisphere of projection, $F(1,7)=7.3, \quad p<.05$. Only when the verbal stimuli were presented with a mask was the right hemisphere appreciably faster than the left $(25 \mathrm{msec})$. When the stimuli were presented without a mask, the overall difference between the hemispheres for identification speed was small $(4 \mathrm{msec})$. A main effect for the presence of a mask was obtained, $F(1,7)=60.0, p<.01$, as it was for retinal locus of the stimulus display, $F(1,7)=100.3, p<.001$. Masked items yielded longer RTs than unmasked items (560 vs. $459 \mathrm{msec}$ ), with foveal presentations producing shorter RTs than peripheral presentations (490 vs. $529 \mathrm{msec})$. Retinal locus of the verbal stimulus items also interacted significantly with the presence of a lateral mask, $F(1,7)=30.2, p<.01$. This interaction reflected less masking effect for stimulus displays presented nearer the fovea than for those presented away from the fovea (74 vs. $128 \mathrm{msec}$ ). 
The nonverbal stimulus items did produce a significant main effect for hemisphere of projection, $F(1,7)=10.0, p<.05$, with right-hemisphere presentations demonstrating shorter RT than lefthemisphere presentations for stimulus identification (642 vs. $701 \mathrm{msec}$ ). Main effects for the presence of a masking stimulus and retinal locus of the display were obtained, $F(1,7)=47.5, p<.001$, and $F(1,7)$ $=27.0, \mathrm{p}<.01$, with masked presentations demonstrating longer RT than unmasked items (738 vs. $605 \mathrm{msec}$ ) and foveal presentations demonstrating shorter RT than peripheral presentations (605 vs. $738 \mathrm{msec}$ ). Retinal locus and masking condition produced a marginally significant interaction, $F(1,7)$ $=5.3, \mathrm{p}<.06$. The difference between the masked and unmasked conditions was less for presentations nearer the fovea than away from the fovea (108 vs. $159 \mathrm{msec}$ ).

\section{Error Data}

The mean percentage of incorrect responses (IR) averaged over subjects for each stimulus display condition are presented in Table 1. Comparing the pattern of errors and corresponding RTs, an increase in errror percentage is associated with an increase in RT. Thus, no speed accuracy trade off occurred and, in general, the accuracy data closely mimic the RT data. A four-factor analysis of variance identical to that performed on the RT data was also performed on the mean percentage of errors made by each subject under each experimental condition. Overall accuracy of response demonstrated significantly fewer errors for right-hemisphere presentations than for left-hemisphere presentations $(10.0 \%$ vs. $14.4 \%), F(1,14)=20.3$, $\mathrm{p}<.001$. The verbal stimulus items produced significantly fewer errors than nonverbal stimulus items $(7.6 \%$ vs. $16.8 \%)$, with $F(1,14)=10.1$, $p<.001$. Hemisphere of projection and type of stimulus yielded a significant interaction, $F(1,14)$ $=11.0, \mathrm{p}<.001$, which reflected a larger difference in identification accuracy between the left- and right-hemisphere presentations for nonverbal $(\mathbf{7 . 6 \%})$ as compared to the hemispheric difference for verbal stimuli $(1.2 \%)$.

The presence of a masking stimulus produced significantly more errors than stimulus presentations occurring without a mask $(17.0 \%$ vs. $7.4 \%)$, with $F(1,14)=21.8, p<.001$. The retinal locus of the stimulus display produced a significant main effect, $\mathrm{F}(1,14)=25.1, \mathrm{p}<.001$, with the $1.9^{\circ}$ displays obtaining fewer errors than the $3.8^{\circ}$ displays $(6.7 \%$ vs. $17.7 \%$ ). Retinal locus of the stimulus display also interacted significantly with hemisphere of projection, $\mathrm{F}(1,14)=8.6, \mathrm{p}<.05$, indicating a smaller difference in error percentage between the hemispheres at the $1.9^{\circ}$ presentations relative to the $3.8^{\circ}$ presentations $(0.8 \%$ vs. $8.0 \%)$. In addition, the retinal locus of the stimulus items interacted significantly with the type of stimulus material, $F(1,14)=13.1, p<.01$. This interaction reflected $a$ smaller difference between types of stimuli in the number of errors made when the presentations were nearer the fovea than when they were away from the fovea $(1.3 \%$ vs. $17.1 \%)$.

Because stimulus type interacted with hemisphere of projection for the error data, a three-factor analysis of variance identical to that performed on the RT data was also performed on the error data obtained from just the verbal stimulus responses and just the nonverbal stimulus responses. For the verbal stimuli, the right hemisphere demonstrated fewer errors than the left $(7.0 \%$ vs. $8.2 \%)$, but this effect was not significant $(p<.20)$. Although the presence of a masking stimulus produced a greater number of errors than stimulus displays presented without a mask $(10.6 \%$ vs. $4.6 \%)$, this effect was only marginally significant for the verbal items, $F(1,7)=5.0, p<.06$. The retinal locus of the stimulus display did demonstrate a significant main effect, however, with items presented nearer the fovea producing fewer errors than items presented away from the fovea $(6.1 \%$ vs. $9.1 \%)$, with $F(1,7)$ $=9.7, \mathrm{p}<.05$.

The nonverbal stimulus items demonstrated a similar pattern of results. Right-hemisphere presentations produced significantly fewer errors than left-hemisphere presentations $(13.0 \%$ vs. $20.6 \%)$, $F(1,7)=18.4, p<.01$. The main effects of masking condition and retinal locus were both significant, with $F(1,7)=17.8, p<.01$, and $F(1,7)=19.6$, $\mathrm{p}<.01$, respectively. More errors were obtained when the stimulus displays were presented with a mask than when they were presented without a mask $(23.5 \%$ vs. $10.1 \%)$, and the $1.9^{\circ}$ stimulus presentations produced fewer errors than the $3.8^{\circ}$ presentations $(7.4 \%$ vs. $26.2 \%)$. Retinal locus interacted significantly with hemisphere of projection for the nonverbal items, $F(1,7)=6.9, p<.05$, reflecting the smaller diffference in error percentages between the hemispheres for presentations nearer the fovea than for presentations away from the fovea $(2.5 \%$ vs. $12.8 \%)$. Retinal locus also interacted significantly with the presence of a lateral mask, $F(1,7)=7.0, p<.05$. This interaction, reflected the smaller difference in the number of errors made between masked and unmasked items when presented at the $1.9^{\circ}$ locus as compared with the $3.8^{\circ}$ presentations $(10.0 \%$ vs. $16.9 \%)$.

\section{DISCUSSION}

Verbal stimulus items presented with a lateral mask to the right hemisphere demonstrated shorter 
RT for identification and generally fewer errors than did presentations to the left hemisphere. Verbal stimulus items presented without masking stimuli also obtained this result but the magnitude of the effect was small and not significant. When hard-to-label nonverbal stimulus items were presented to each hemisphere for identification, the right hemisphere produced faster responding and fewer errors for both masked and unmasked presentations. Taken together, this pattern of results indicates that the matching-to-memory stimulus identification procedure does have an effect on hemispheric differences. However, the effect is greater for nonverbal stimulus materials than for verbal stimulus materials.

When presented without a lateral mask, very little hemispheric difference in processing speed or accuracy for verbal stimuli was observed. Previous studies employing verbal items and a manual RT nonnaming identification task have generally found a left-hemisphere advantage (Isseroff et al., 1974; Rizzolatti et al., 1971; Umilta et al., 1972; White, 1973b). However, these previous studies employed a go/no-go procedure which had subjects respond only when a positive member of a set of items was presented. When a positive item did not appear, the subject was to do nothing. The left-hemisphere advantage for these studies could have arisen from the subject's attempts to maintain the positive set by rehearsing the names or labels of the items. This effect has been reported by Hellige and Cox (1976), who found a strong left-hemisphere advantage for the recognition of verbal stimuli when subjects were concurrently rehearsing additional verbal items.

The present study's procedure attempted to reduce these rehearsal effects with a response situation that would encourage a visual coding of the stimulus and hence a right-hemisphere advantage. However, the obtained effect was weak for the unmasked letters and may indicate that not all the subjects were employing right-hemisphere processes to respond to these stimulus items. Examination of individual subject RT profiles for this stimulus condition revealed that out of eight subjects, two demonstrated slightly faster response times for stimuli projected to the right hemisphere, two demonstrated slightly faster response times for stimuli projected to the left hemisphere, and four subjects demonstrated a mixed pattern (the response times depending upon the retinal locus of stimulation as well as the hemisphere of projection). This analysis implies that, although a visual code can be employed for unmasked letter stimuli, the highly overlearned letter names and the associated language functions they promote may operate to bias cerebral activation to the left hemisphere in spite of a task situation favoring the right hemisphere's processing mode. Such a left-hemisphere activation could have reduced the influence of the right hemisphere in the present study and thereby reduced the effectiveness of using just a visual code for the letters (see Kinsbourne, 1970; Klein, Moscovitch, \& Vigna, 1976). If this interpretation is correct, activation of the left hemisphere, because of a readily labelable stimulus, would seem to be a very stable effect, since each subject completed 320 practice trials before the experimental trials were begun. The extensive warm-up procedure was adopted explicitly to insure observation of "steady-state" hemispheric processing rather than transient effects due to task adaptation (Hellige, 1976; Ward \& Ross, 1977). It would appear that even with large numbers of practice trials in a task situation that encourages use of a visual code, the hemispheric influence of a welllearned label, such as those available for letters of the alphabet, cannot be easily eliminated.

Nonverbal items produced faster and more accurate responding for right- than for left-hemisphere presentations, regardless of whether the stimulus was laterally masked or not. This finding agrees with previous research employing a manual RT identification task and faces as nonverbal stimuli (Geffen et al., 1971; Moscovitch et al., 1976; Rizzolatti et al., 1971). However, this finding is contrary to previous studies that employed outlines of common objects or geometric forms and found inconsistent hemispheric effects (Juola, 1973; Klatzky \& Atkinson, 1971). Since these "nonverbal" stimuli do have well-learned labels, they could have been rehearsed given the procedure employed. It is reasonable to conclude that the availability of a label during responding could affect hemispheric processing differences for stimulus identification by influencing the left hemisphere during the task. Such an effect could therefore account for the ambiguous findings in studies employing labelable "nonverbal" stimuli.

The presence of lateral masks in the present study had a clear and consistent effect on stimulus identification. For both verbal and nonverbal items, RT was slowed and more errors occurred when the target item was presented with masking stimuli. These results agree with the general findings of previous studies that a lateral mask interferes with stimulus identification (Hollingsworth \& Wolford, cited in Wolford, 1975; Wolford, 1975) and extend their application to stimuli which are not letters. However, when letter stimulus materials were presented with lateral masks, the right-hemisphere presentations produced faster RT and generally fewer errors. This finding disagrees with previous observations of left-hemisphere superiority for accuracy and speed of identification when masking stimuli were presented (Bouma, 1974; Bradshaw 
et al., 1977). In the present investigation, both masked verbal and masked nonverbal items demonstrated faster and more accurate identification performance for right-hemisphere presentations. Again, the primary difference between the present and previous studies is the nature of the response task: previous studies either had subjects name the item or match it to a previously memorized item, thus encouraging rehearsal and left-hemisphere processing. When this bias is removed from the response situation by having subjects directly indicate which laterally masked item was presented, then the right hemisphere's holistic and visuospatial processing (Bogen, 1969; Levy, 1974; Nebes, 1971, 1972) can produce superior identification performance. Thus, under degraded stimulus conditions, subjects apparently find the visual code available through right-hemisphere processing more efficient than attempting to employ a verbal code or perform some form of feature analysis of the stimulus (Hellige, 1975).

The observed effects of retinal locus were also consistent: faster RT and more accurate responding when both verbal and nonverbal stimuli were presented nearer the fovea at the $1.9^{\circ}$ locations than when they were presented at the more peripheral $3.8^{\circ}$ locations. This effect agrees with previous studies of the relationship between retinal position and stimulus identification (Estes \& Wolford, 1971; Hershenson, 1969; White, 1970; Wolford \& Hollingsworth, 1974). However, the present study obtained more pronounced retinal locus effects for the nonverbal stimuli rather than for the verbal stimuli. This finding may indicate that the effects of retinal locus are mediated by the availability of the stimulus label. Stimulus items with welllearned verbal codes could activate left-hemisphere processing and decrease the reliance on a purely visual code. Stimulus items without readily available verbal codes would not benefit from such a process and would, therefore, produce overall longer RT and more errors, especially for the peripheral presentations.

The retinal locus of the stimulus presentation did interact significantly with hemisphere of projection for the error data and seems to indicate that righthemisphere presentations were less affected by retinal eccentricity than left-hemisphere presentations. This finding agrees with some previous observations (Lefton \& Haber, 1974, Experiment 3; White, 1973b), but disagrees with others (Hirata \& Bryden, 1976; McKeever \& Gill, 1972a; Wolford \& Hollingsworth, 1974), where left-hemisphere presentations produced better identification over the various retinal loci employed. Again, the type of task employed in the present study would encourage visuospatial processing rather than reliance on stimulus labels for identification (the response procedure of these previous studies.). If this were the case, then a stimulus image that was degraded because of a peripheral input location should benefit from such an analysis and reflect shorter RT and lower error rates for right-hemisphere presentationsexactly what was observed for both stimulus conditions of the present study.

In sum, the type of processing task required of subjects strongly determines which hemisphre will process incoming visual information more quickly and accurately. When the influence of stimulus names can be reduced and a visuospatial analysis or visual coding of the stimulus encouraged, the right hemisphere appears to be superior to the left for both nonverbal and verbal stimuli. However, the powerful influence of a well-learned label (at least for letters of the alphabet) can apparently erode this effect through left-hemisphere activity, even within a nonnaming response task. In addition, both the type of task as well as the type of stimulus appear to interact with the presence of a lateral masking stimulus and retinal locus to some extent. Whether or not these variables will demonstrate similar findings for processing tasks other than stimulus identification is a question for future research.

\section{REFERENCES}

Bartram, D. J. The role of visual and semantic codes in object naming. Cognitive Psychology, 1974, 6, 325-356.

Bogen, J. E. The other side of the brain II: An appositional mind. Bulletin of the Los Angeles Neurological Societies, 1969, 34, 135-162.

Bouma. H. Visual interference in the parafoveal recognition of initial and final letters of words. Vision Research. $1974,14,767-781$.

Bradshaw, J. L., Bradley, D., Gates, A., \& Patterson, D. Serial, parallel, or holistic identification of single words in the two visual fields? Perception \& Psychophysics, 1977. 21, 431-438.

BRYDEN, M. P. Tachistoscopic recognition of nonalphabetical material. Canadian Journal of Psychology, 1960, 14, 78-86.

BRyden, M. P. Tachistoscopic recognition, handedness, and cerebral dominance. Neuropsychologia, 1965, 3, 1-8.

BRYDEN, M. P. Left-right differences in tachistoscopic recognition: Directional scanning or cerebral dominance? Perceptual \& Motor Skills, 1966, 23, 1127-1134.

BRYDEN, M. P. Perceptual asymmetry in vision: Relation to handedness, eyedness, and speech lateralization. Cortex, 1973, 9, 418-435.

Bryden, M. P., \& Rainey, C. A. Left-right differences in tachistoscopic recognition. Journal of Experimental Psychology, 1963, 66, 568-571.

Carmon, A., Nachshon, I., Isseroff, A., \& Kleiner, M. Visual field differences in reaction times to Hebrew letters. Psychonomic Science, 1972, 28, 222-224.

CoHen, G. Hemispheric differences in a letter classification task. Perception \& Psychophysics, 1972, 11, 139-142.

Conen, G. Hemispheric differences in the effects of cuing in visual recognition tasks. Journal of Experimental Psychology: Human Perception and Performance, 1975, 1, 366-373.

Cohen, G. Components of the laterality effect in letter recog- 
nition: Asymmetries in iconic storage. Quarterly Journal of Experimental Psychology, 1976, 28, 105-114.

DeE, H. L., \& Fontenot, D. J. Cerebral dominance and lateral differences in perception and memory. Neuropsychologia, 1973, 11, 167-173.

Estes, W. K., \& Wolford, G. L. Effects of spaces on report from tachistoscopically presented letter strings. Psychonomic Science, 1971, 25, 77-79.

Fontenot, D. J. Visual field differences in the recognition of verbal and nonverbal stimuli in man. Journal of Comparative and Physiological Psychology, 1973, 85, 564-569.

Fontenot, D. J., \& Benton, A. L. Perception of direction in the right and left visual fields. Neuropsychologia, 1972, 10. 447-452.

Forgays, D. G. The development of differential word recognition. Journal of Experimental Psychology, 1953, 45, 165-168.

Gazzaniga, M. S., \& Sperry, R. W. Language after section of the cerebral commissures. Brain, 1967, 90, 131-148.

Geffen, G., Bradshaw, J. L., \& Nettreton, N. C. Hemispheric asymmetry: Verbal and spatial encoding of visual stimuli. Journal of Experimental Psychology, 1972, 95, 25-31.

GefFen, G., Bradshaw, J. L., \& Wallace, G. Interhemispheric effects on reaction time to verbal and nonverbal visual stimuli. Joumal of Experimental Psychology, 1971, 87, 415.422.

Geschwind, N. The organization of language and the brain. Science, 1970, 170, 940-944.

Hannay, H. J., \& Malone, D. R. Visual field effects and short-term memory for verbal materal. Neuropsychologia, 1976, 14, 203-209.

Hellige, J. B. Hemispheric processing differences revealed by differential conditioning and reaction time performance. Journal of Experimental Psychology: General, 1975, 104, 309-326.

Hellige, J. B. Changes in same-different laterality pattern as a function of practice and stimulus quality. Perception \& Psychophysics, 1976, 20, 267-273.

Hellige, J. B., \& Cox, P. J. Effects of concurrent verbal memory on recognition of stimuli from the left and right visual fields. Journal of Experimental Psychology: Human Perception and Performance, 1976, 2, 210-221.

Hershenson, M. Perception of letter arrays as a function of absolute retinal locus. Journal of Experimental Psychology. $1969,80,201-202$.

Hilliard, R. D. Hemispheric laterality effects on a facial recognition task in normal subjects. Cortex, 1973, 9, 246-258.

Hines, D., Satz, P., \& Clementino, T. Perceptual and memory components for the superior recall of letters from the right visual half-fields. Neuropsychologia, 1973, 11, 175-180.

Hirata, K., Bryden, M. P. Right visual field superiority for letter recognition with partial report. Canadian Journal of Psychology, 1976, 30, 134-139.

Isseroff, A., Carmon, A., \& Nachshon, I. Dissociation of hemifield reaction time differences from verbal stimulus directionality. Journal of Experimental Psychology, 1974, 103, $145 \cdot 149$.

Juol A, J. F. Repetition and laterality effects on recognition memory for words and pictures. Memory \& Cognition, 1973, 1, 183-192.

KImURA, D. Dual functional asymmetry of the brain in visual perception. Neuropsychologia, 1966, 4, 275-285.

KimurA, D., \& Dunford, M. Normal studies on the function of the right hemisphere in vision. In S. J. Dimond \& J. G. Beaumont (Eds.), Hemisphere function in the human brain. New York: Wiley, 1974.

KinsBourne, M. The cerebral basis of lateral asymmetries in attention. Acta Psychologica, 1970, 33, 193-201.

KLATZKY, R. L. Visual and verbal coding of laterally presented pictures. Journal of Experimental Psychology, 1972, 96, 439-448.
KLAtzky, R. L., \& Atkinson, R. C. Specialization of the cerebral hemispheres in scanning for information in shortterm memory. Perception \& Psychophysics, 1971, 10, 335-338.

Klein, D., Moscovitch, M., \& Vigna, C. Attentional mechanisms and perceptual asymmetries in tachistoscopic recog. nition of words and faces. Neuropsychologia, 1976, 14, 55-66.

Lefton, L. A., \& HABer, R. N. Information extraction from different retinal locations. Journal of Experimental Psychology, 1974, 102, 975-980.

LEVY, J. Psychobiological implications of bilateral asymmetry. In S. J. Dimond \& J. G. Beaumont (Eds.), Hemisphere function in the human brain. New York: Wiley, 1974.

Levy, J., \& Trevarthen, C. Metacontrol of hemispheric function in human split-brain patients. Joumal of Experimental Psychology: Human Perception \& Performance, 1976, 2, 299-312.

Levy, J., Trevarthen, C., \& Sperry, R. W. Perception of bilateral chimeric figures following hemisphere de-connection. Brain, 1972, 95, 61-78.

McKeever, W. F., \& Gill, K. M. Interhemispheric transfer time for visual stimulus information varies as a function of the retinal locus of stimulation. Psychonomic Science, 1972, 26, 308-310. (a)

McKeever, W. F., \& Gill, K. M. Visual half-field differences in masking effects for sequential letter stimuli in the right and left handed. Neuropsychologia, 1972, 10, 111-117. (b)

McKeever. W. F., Gill, K. M., \& VanDeventer, D. A. Letter versus dot stimuli as tools for "splitting the normal brain with reaction time." Quarterly Journal of Experimental Psychology, 1975, 27, 363-373.

MCKeEver. W. J., \& Huling, M. D. Left cerebral hemisphere superiority in tachistoscopic word recognition performances. Perceptual and Motor Skills, 1970, 30, 763-766.

MilneR, B. Interhemispheric differences in the localization of psychological processes in man. British Medical Bulletin, 1971, 27, 272-277.

Mishkin, M., \& Forgays, D. G. Word recognition as a function of retinal locus. Journal of Experimental Psychology, 1952, 43, 43.48.

Moscovitch, M., \& Catrin, J. Interhemispheric transmission of information: Measurement in normal man. Psychonomic Science, 1970, 18, 211-213.

Moscovitch, M., Scullion, D., \& Christie, D. Early versus late stages of processing and their relation to functional hemispheric asymmetries in face recognition. Journal of Experimental Psychology: Human Perception and Performance, 1976, 2, 401-416.

NebEs, R. D. Superiority of the minor hemisphere in commissurotomized man for the perception of part-whole relations. Cortex, 1971, 7, 333-347.

NebEs, R. D. Dominance of the minor hemisphere in commissurotomized $\operatorname{man}$ in a test of figural unification. Brain, 1972, 95, 633-638.

NeIl, D. O., S Ampson, H., \& Gribben, J. A. Hemiretinal effects in tachistoscopic letter recognition. Journal of Experimental Psychology, 1971, 91, 129-135.

Orbach, J. Retinal locus as a factor in the recognition of visually perceived words. American Joumal of Psychology, 1953, 65, 555-562.

Paivio, A., \& ERnest, C. H. Imagery ability and visual perception of verbal and nonverbal stimuli. Perception \& Psychophysics, 1971, 10, 429-432.

Paterson, A., \& Zangwill, O. L. Disorders of visual space perception associated with lesions of the right cerebral hemisphere. Brain, 1944, 67, 331-358.

Posner, M. I. Abstraction and the process of recognition. In G. Bower \& K. Spence (Eds.), Psychology of learning and motivation (Vol. 3). New York: Academic Press, 1969.

Posner, M. I., \& Mitchell, R. F. A chronometric analysis 
of classification. Psychological Review, 1967, 74, 392-409.

Potrs, G. R. Use of a campus-wide timesharing system to run reaction time experiments. Behavior Research Methods \& \& Instrumentation, 1976, 8, 179-181.

Rizzolatti, G., Umilta, C., \& Berlucchi, G. Opposite superiorities of the right and left cerebral hemispheres in discriminative reaction time to physiognomical and alphabetical material. Brain, 1971, 94, 431-442.

Scheerer, E. Task requirement and hemifield asymmetry in tachistoscopic partial report performance. Acta Psychologica, 1974, 38, 131-147.

SPERRY, R. W. Lateral specialization in the surgically separated hemispheres. In F. Schmitt \& F. Worden (Eds.), The neurosciences: Third study program. Cambridge: MIT Press, 1974.

Umilta, C., Frost, N., \& Hyman, R. Interhemispheric effects on choice reaction times to one-, two-, and threeletter displays. Journal of Experimental Psychology, 1972. 93. 198-204.

Umilta, C., Rizzolatti, G., Marzi, C. A., Zamboni, G., Franzini, C., Camarda, R., \& Berlucchi, G. Hemispheric differences in the discrimination of line orientation. Neuropsychologia, 1974, 12, 165-174.

WARD, T. B., \& Ross, L. E. Laterality differences and practice effects under central backward masking conditions. Memory \& Cognition, 1977, 5, 221-226.

WhITE, M. J. Order of report and letter structure in tachistoscopic recognition. Psychonomic Science, 1969, 17, 364-365.

WhITE, M. J. Retinal locus and the letter-span error function. Perception \& Psychophysics, 1970, 8, 107-109.

White, M. J. Visual hemifield differences in the perception of letters and contour orientation. Canadian Journal of Psychology, 1971, 25, 207-212.
WhITE, M. J. Signal-detection analysis of laterality differences: Some preliminary data, free of recall and report-sequence characteristics. Journal of Experimental Psychology, 1973. 83, 174-176. (a)

WhITE, M. J. Vocal and manual response latencies to bilateral and unilateral tachistoscopic letter displays. Quarterly Journal of Experimental Psychology, 1973, 25, 41-47. (b)

Wolford, G. L. Perturbation model of letter identification. Psychological Review, 1975, 82, 184-199.

Wolford, G. L., \& Hollingsworth, S. Retinal location and string position as important variables in visual information processing. Perception \& Psychophysics, 1974, 16, 437.442.

Worral, N., \& Coles, P. Visual field differences in recognizing letters. Perception \& Psychophysics, 1976, 20, 21-24.

WYKE, M., \& ETTLINGER, G. Efficiency of recognition in the left and right visual fields. Archives of Neurology, 1961. 5. 659-665.

Young, A. W., \& Ellis, H. D. An experimental investigation of developmental differences in ability to recognize faces presented to the left and right cerebral hemispheres. Neuropsychologia, 1976, 14, 495-498.

\section{NOTE}

1. A complete description of the stimuli, procedure, and results of the pretest may be obtained from the author.

(Received for publication November 10, 1977; revision accepted April 3, 1978.) 